\title{
Are all sovereigns equal? A test of the common determination of sovereign spreads in the euro area
}

\author{
Heather D. Gibson · Stephen G. Hall · George S. Tavlas
}

\begin{abstract}
With the outbreak of the Greek financial crisis in late 2009, spreads on Greek (and other) sovereigns reached unprecedented levels. Using a panel data of euro-area countries, we test whether the markets treated all euro-area countries in an equal manner over the period 1998:m1 to 2012:m6. An $F$ test of the pooling assumptions suggests that Greece, Ireland, and Portugal were not part of the overall pool. In a separate test on the individual coefficients we find that the coefficients on these three countries moved in a similar direction away from the pool, suggesting that markets treated these three countries more acutely than the rest of the pool.
\end{abstract}

Keywords Euro area financial crisis - Sovereign spreads $\cdot$ Panel data tests

JEL Classification $\mathrm{C} 33 \cdot \mathrm{G} 12 \cdot \mathrm{E} 63$

\section{Introduction}

The years following the inception of the euro in 1999 have seen some unprece-dented movements of sovereign spreads of euro-area countries (Fig. 1). This develop-ment is especially striking since an aim of the common currency was to enhance stability among the participating countries following the decade of the 1990s, which saw a number of currency crises (including in Europe in the early 1990s). These currency crises are now generally interpreted within the paradigm of the

\footnotetext{
H. D. Gibson · G. S. Tavlas

Bank of Greece, Athens, Greece

S. G. Hall (B)

University of Leicester, Leicester, UK e-mail: s.g.hall@le.ac.uk
} 


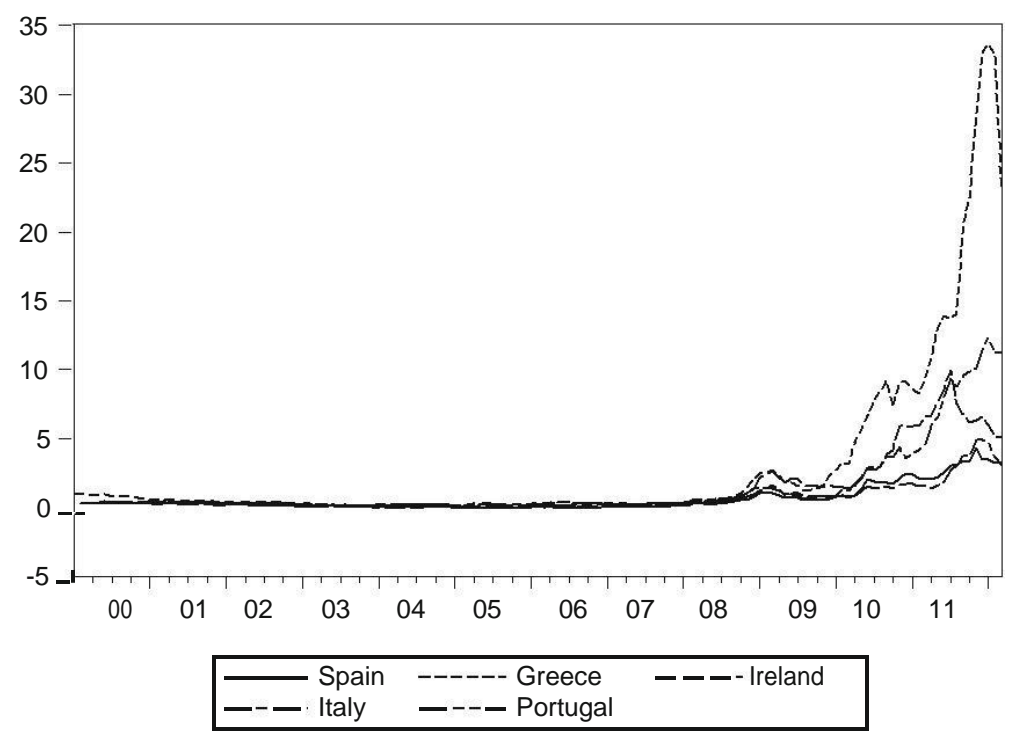

Fig. 1 Government bond yield spreads (10-year) in euro-area countries (relative to Germany)

third-generation currency crisis models, which emphasize the effects of market speculation and multiple equilibria, rather than fundamentals. Recently, Grauwe and Ji ( 2013) have made a theoretical argument to interpret the euro-area sovereign debt crises as a new manifestation of a speculative market attack on a sovereign, but in this case through yield spreads rather than through foreign exchange rates, since currency crises have essentially been precluded by the creation of the euro.

In an earlier paper ( Gibson et al. 2012), we examined the determinants of spreads between the 10-year benchmark Greek government bond and the German 10 -year sovereign. Our data sample was monthly and covered the period from January 2000 through September 2010. Thus, our data covered the pre-crisis period (i.e., the period prior to the fall of 2009) and the early part of the crisis period. Our earlier study had the following two objectives. First, we sought to determine the extent to which credit ratings assigned by the credit agencies were reflected in risk premia, given that credit ratings typically are constructed to reflect the present and prospective fundamentals of an economy. Second, in a separate empirical analysis, we sought to directly estimate the impact of the fundamentals on Greek spreads. Our results suggested that (i) the credit ratings did not capture all the factors that impacted on spreads and (ii) spreads were significantly below what would have been predicted by the fundamentals during the mid-2000s, but significantly above what had been predicted by the fundamentals for much of 2010 .

\footnotetext{
$\overline{1}$ The extent, however, that the increase in sovereign spreads during 2011 and 2012 in Greece, for example, possibly reflected expectations of a possible departure of that country from the euro area, currency risk may not have been completely eliminated.
} 
In this paper, we test the notion that the markets have treated all the countries of the euro zone in an equal manner. In other words, if De Grauwe and Ji's conjecture is wrong, and there was no speculative attack in the sovereign bond markets against any euro-area country, then we would expect that the fundamental drivers of sovereign spreads would be the same for each country and have a similar effect. If this is not the case, however, it would indicate that the speculative attack argument may have some validity.

The paper is organized as follows. Sect. 2 provides some theoretical background into the determinants of spreads between sovereign debt yields in one country relative to another that share a common currency. In Sect. 3, we discuss the data used. Section 4 outlines a panel data model for sovereign spreads in the euro area and conducts some pooling tests. Section 5 concludes.

\section{The determinants of spreads}

In general, the determinants of the spreads between sovereign debt yields in one country relative to another that share a common currency reflect the relative risk of default across countries. In this section, we develop a simple model of yields - and, thus, of spreads across countries - on sovereign debt.

Assume that investors are risk neutral and that, in addition to risky sovereign debt, they also have access to a risk-free bond. Assume, also, that the investors' discount factor is $\beta$. For the sake of simplicity consider a two-period model; longer time horizons make no difference to the results.

The typical investor $i$ chooses the quantity of discount bonds to buy, $b_{i}$, at price $q$ in order to maximize lifetime utility:

$$
C_{i 1}+\beta C_{i 2}=Y_{i 1}-q b_{i}+\beta F(b) b_{i}+Y_{i 2},
$$

where $C_{i 1}$ and $C_{i 2}$ are consumption in the first and second periods, respectively, $Y$ $i j$ are the corresponding levels of output, and $F(b)$ is the probability of debt repayment, where $b$ is the total amount of discount bonds issued by the particular sovereign. Note that because of risk neutrality there is no interior portfolio selection - that is, the investor will buy the asset with the highest expected rate of return. The first-order condition (FOC) takes the form:

$$
q=\beta F(b)
$$

so the inverse of the spread over the risk-free bond, and $q / \beta$ is equal to the probability of repayment. When sovereign debt is risk free i.e., $F(b)=1$, then $q=\beta$ and the spread is zero.

In order to determine the spread we need to determine the probability of repayment, $F(b)$. This is computed from the optimization problem of the sovereign. The sovereign's utility is given by

$$
U\left(C_{1}\right)+\delta U\left(C_{2}\right)=U\left(Y_{1}+q b\right)+\delta U\left(Y_{2}-\min \left\{b+b_{0}, k Y_{2}\right\}\right),
$$


where $\delta<\beta$ is the sovereign's discount factor (the inequality guarantees that the sovereign is a borrower), $b_{0}$ is long-term debt due in period 2 , and $k$ is a scalar capturing the cost of default. That is, if the sovereign does not pay back, the sovereign suffers an output loss of $k Y_{2}$ (cost of sanctions). $Y_{2}=Y+e$ is the level of output, where $Y$ is a constant and $e$ a random variable.

While the FOC of this optimization problem can be used to compute the optimal $b$, the properties of $F(b)$ can be established simply without making use of the FOC. In particular, the sovereign repays $k$ if what he pays back is less that the cost he would have suffered in the case of default, that is, when $b+b_{0}<k Y_{2}$. Hence the probability of repayment, $F(b)$, is given by $F(b)=F\left(b+b_{0}<k Y_{2}\right)=F\left(b<k Y_{2}-b_{0}\right)$. From the properties of the probability distribution function it follows that

- $\mathrm{d} F / \mathrm{d} b_{0}<0$, that is, the larger the level of outstanding debt, the lower is the probability of repayment $(F)$ and thus the larger is the $\operatorname{spread}(\beta / \mathrm{q})$.

- $\mathrm{d} F / \mathrm{d} Y>0$, that is, the worse the future economic prospects (a lower expected output), the lower is the probability of repayment $(F)$ and thus the larger is the $\operatorname{spread}(\beta / q)$.

- $\mathrm{d} F / \mathrm{d}(q b)<0$, that is, the larger the trade (current account) deficit, the lower is the probability of repayment $(F)$ and thus the larger is the $\operatorname{spread}(\beta / \mathrm{q})$. Note that $q b=C_{1}-Y_{1}$ is the trade (current account) deficit.

\section{The data}

The data used are for a panel of euro-area countries comprising Austria (OE), Belgium (BE), Finland (FN), France (FR), Greece (GR), Ireland (IR), Italy (IT), The Netherlands (NL), Portugal (PG), and Spain (ES), where appropriate variables are measured relative to the corresponding variables for Germany; consequently, Germany does not explicitly appear as a panel member. The data are monthly and the panel is unbal-anced; most data are, however, available over the period $1998 \mathrm{~m} 1$ to $2012 \mathrm{~m} 6$. In those cases for which the original data are quarterly, the data have been interpolated to a monthly frequency. The dependent variable is the yield spread between the 10 -year benchmark government bond yield of the country in question and that of Germany. Our explanatory variables are measures of macroeconomic fundamentals as suggested by the model in Sect. 3; we ask whether it is possible to identify the fundamental long-run determinants of spreads. We use the following three fiscal variables: (1) the general government consolidated gross debt-to-GDP ratio (expressed as a percentage), inter-polated from quarterly to a monthly frequency. An increase in the ratio would be expected to raise spreads. (2) The general government fiscal balance as a percentage of GDP, again interpolated to monthly frequency. The fiscal balance is recorded as a surplus, so that a rise in the surplus would be expected to reduce spreads (i.e., the sign of the coefficient should be negative). (3) A cumulated fiscal news variable that we used in our earlier paper. $^{2}$ This variable tracks revisions to the projected fiscal balance for the contemporaneous and forthcoming year based on the European Commission's

\footnotetext{
2 This variable is semi-annual but is not interpolated in the usual way to get monthly data; rather it is constructed to prevent news events occurring before they were actually announced.
} 
semi-annual (spring and autumn) forecasts. Positive values represent good news (i.e., sign of the coefficient should be negative. Variables capturing competitiveness include each country's Harmonised Index of Consumer Prices (HICP, all items index) relative to that of Germany (relative prices) and its current account on the balance of payments (as a proportion of GDP). Growth is an important determinant of debt sustainability and, hence, we include thepercentage change in real GDP, interpolated from quarterly GDP data.

\section{A panel analysis for the euro area}

To investigate whether spreads appear to be determined by similar fundamentals across the euro area, we first present our preferred fixed-effects panel regression for the spreads as a function of all the variables under consideration (Table 1). All the variables except the fiscal balance have the correct sign and are significant at the $10 \%$ level. The fiscal variable has a positive sign, meaning that a rise in the fiscal surplus (fall in the deficit) causes spreads to rise. We discuss this result further below.

We now turn to the pooling assumption that underlies these estimates. This assumption amounts to the statement that financial markets treat each country in a similar way, that is, if any two countries exhibit the same change in their fundamentals, then the market should assign the same change in spreads to each country. If the pool-ing assumption is violated, it implies that some countries are treated differently from others even though the changes in their respective fundamentals are identical.

There is an extensive literature on testing the pooling assumption in panel data, see for example the excellent section in chap. 4 of Baltagi (2008) or the survey of the issue in Baltagi et al. ( 2008). The usual issue being tested by pooling tests is the null hypothesis that all the parameters of a particular model may be pooled jointly. Here, however, we want to ask a slightly different question, we wish to ask if any piece of information on any one country is being treated differently from the way it is being used for the other countries. So rather than testing the joint pooling of all the parameters we wish to focus on just one parameter at a time. Similarly, if we wanted to estimate the average effect across countries and (as it is clear below that the) pooling assumption does not hold, we might want to estimate individual country models and then average them in some way. Following the mean group estimator or the pooled mean group estimator of Pesaran and Smith ( 1995) and Pesaran et al. ( 1999) would be two possible ways forward. However, again, this is not our objective as we are explicitly investigating how an individual country is being treated differently from the rest.

The way we test this assumption is by applying a dummy variable test of each coefficient for each country individually. In general, let the panel regression have the following form:

$$
\begin{array}{r}
y_{i t=0 i+j} \beta x_{i j t+}{ }_{i t}^{\nu^{\prime}}, \\
j=1
\end{array}
$$

where the pooling assumption may be seen by the restriction that $\beta_{j} i=\beta_{j}$ alli. Now to relax this assumption for variable $m$ and country $l$, we create a dummy variable 
which has the following form:

$$
D_{i j t}=0 \text { for } i_{-}=l \text { and } j_{-}=m \text { otherwise } D_{i j t}=1 \text {. }
$$

We then run the following regression:

$$
y_{i t}=\beta_{0 i}+{ }_{j=1}^{k} \beta_{j} x_{i j t}+\beta^{*} D_{i j t} x_{i j t}+v_{i t} .
$$

The pooling assumption may then be tested by a $t$ test on $\beta^{*}$, where the unpooled coefficient on variable $m$ for country $l$ would be $\beta_{l m}=\beta_{m}+\beta^{*}$. Note that both the sign and the significance of the $t$ test on $\beta^{*}$ are important, as the sign tells us in which direction the unpooled coefficient would move and the significance tells us

\begin{tabular}{|c|c|c|c|c|}
\hline Variable & Coefficient & Std. error & $t$ Statistic & Prob. \\
\hline Constant & -7.019 & 0.361 & -19.462 & 0.000 \\
\hline $\begin{array}{l}\text { Current account surplus } \\
\text { Relative prices }\end{array}$ & $\begin{array}{l}-1.088 \\
18.458\end{array}$ & $\begin{array}{l}0.634 \\
1.624\end{array}$ & $\begin{array}{l}-1.717 \\
11.363\end{array}$ & $\begin{array}{l}0.086 \\
0.000\end{array}$ \\
\hline Fiscal balance & 0.080 & 0.009 & 8.526 & 0.000 \\
\hline Debt & 0.112 & 0.005 & 22.209 & 0.000 \\
\hline Fiscal news & -0.002 & 0.0007 & -2.101 & 0.036 \\
\hline $\begin{array}{l}\text { Real growth } \\
\text { Fixed effects (cross) }\end{array}$ & -84.218 & 13.096 & -6.431 & 0.000 \\
\hline $\begin{array}{l}\text { Belgium } \\
\text { Spain }\end{array}$ & $\begin{array}{l}-3.453 \\
2.228\end{array}$ & & & \\
\hline Finland & 2.310 & & & \\
\hline France & 0.317 & & & \\
\hline $\begin{array}{l}\text { Greece } \\
\text { Ireland }\end{array}$ & $\begin{array}{l}-2.389 \\
3.775\end{array}$ & & & \\
\hline $\begin{array}{l}\text { Italy } \\
\text { Netherlands }\end{array}$ & $\begin{array}{l}-4.317 \\
1.534\end{array}$ & & & \\
\hline $\begin{array}{l}\text { Austria } \\
\text { Portugal } \\
2\end{array}$ & $\begin{array}{l}-0.054 \\
1.071\end{array}$ & & & \\
\hline$R^{2}$ & 0.545 & \multicolumn{2}{|c|}{ Mean dependent var } & 0.794 \\
\hline $\begin{array}{l}\text { Adjusted } R \\
\text { S.E. of regression }\end{array}$ & $\begin{array}{l}0.540 \\
1.674\end{array}$ & \multicolumn{2}{|c|}{$\begin{array}{l}\text { S.D. dependent var } \\
\text { Akaike info criterion }\end{array}$} & $\begin{array}{l}2.468 \\
3.879\end{array}$ \\
\hline Sum squared resid & 4177.360 & \multicolumn{2}{|c|}{ Schwarz criterion } & 3.935 \\
\hline $\begin{array}{l}\text { Log likelihood } \\
F \text {-statistic }\end{array}$ & $\begin{array}{l}-2906.578 \\
118.945\end{array}$ & \multicolumn{2}{|c|}{$\begin{array}{l}\text { Hannan-Quinn criter. } \\
\text { Durbin-Watson stat }\end{array}$} & $\begin{array}{l}3.900 \\
0.108\end{array}$ \\
\hline Prob ( $F$-statistic) & 0.000 & & & \\
\hline
\end{tabular}

Table 1 The preferred fixed-effects panel regression (1998m1 to 2012m6)

Dependent variable: spread on 10-year benchmark government bond yields between the relevant country and Germany. Cross sections included: 10. Total pool (unbalanced) observations: 1507 
if this is significantly different from zero. This test is equivalent to the Chow test described in Baltagi ( 2008) chap. 4 when the chow test is applied to only one country and one parameter. However, as Baltagi (2008) points out, to be correct it rests on the assumption that $\nu_{i} t$ is normally distributed with a constant variance; this is unlikely to be the case especially given the group of countries we are examining here, as it is possible that there may be both cross-section or time heteroskedasticity. We can allow for this using a range of robust covariance matrices in the calculation of the $t$ test; there are of course a number of ways of calculating these matrices and we have chosen to use the White cross-section correction and the White period correction. ${ }^{3}$ In the results below, typically the cross-section correction gives $t$ values that are a little higher (in absolute terms) than the standard one, and the period one gives a result that is quite a lot lower. This is to be expected as there is very little cross-section heteroskedasticity as the dependent variables are all quite similar while there is considerable time-series heteroskedasticity given that the spreads move around considerably toward the end of the period during the financial crises.

Table 2 presents the results of this test for each variable and each country in the above panel regression.

To interpret the results, we focus on the results for Greece, which is the country in which the euro-area crisis originated in late $2009 .{ }^{4}$ Consider, then, the top row of Table 2 for Greece. We see that we can accept the pooling assumption only for the deficit-toGDP ratio at a conventional $95 \%$ confidence level. However, we strongly reject the pooling assumption for the current account to GDP ratio, relative prices, the debt stock, cumulative fiscal news, and GDP growth. In the case of the current account, the sign of the coefficient on the effect of the Greek current account is positive and overturns the negative coefficient in the pooled model. This might be explained by the fact that in the latter part of the sample, when the Greek spreads were especially high, the current account deficit was falling as a result of a deep recession. In the case of relative prices, the individual country effect for Greece suggests that the impact of relative prices on spreads is larger than that suggested by the pooled model. Similarly for the other variables, the Greek coefficients suggest that they have a stronger effect on spreads than those in the pooled model. Thus, the coefficient on debt is positive, which means that the total (unpooled) coefficient on Greek debt is larger than the average pooled coefficient for the other countries. If we then look down the debt column, we can see that every other country (except Portugal) has a negative " $t$ " test and that a number of coefficients are significant, so all these countries would have a smaller effect from the debt-to-GDP ratio than suggested by the pooled results. Even in the case of Portugal, where the " $t$ " test is positive, the coefficient is still much smaller than the corresponding coefficient for Greece and it is also insignificant, indicating that while markets priced poor fundamentals at a high rate into Portuguese spreads, they priced them at an even higher rate into Greek spreads.

\footnotetext{
3

We have chosen these two not only partly because they deal with the two main possible types of heteroskedasticity, cross section and time series, but also partly because having tried a number of other adjust-ments these proved to give the two extremes of correction from the standard test and hence they give a range of possible adjustment.

See Gibson et al. ( 2012) for a discussion of the unfolding of the euro-area crisis.
} 
Table 2 Pooling tests

\begin{tabular}{|c|c|c|c|c|c|c|c|c|c|c|c|c|}
\hline & \multicolumn{2}{|c|}{$\begin{array}{l}\text { Current account } \\
\text { surplus to GDP }\end{array}$} & \multicolumn{2}{|c|}{ Relative prices } & \multicolumn{2}{|c|}{$\begin{array}{l}\text { Fiscal balance- } \\
\text { to-GDP ratio }\end{array}$} & \multicolumn{2}{|c|}{$\begin{array}{l}\text { Debt-to-GDP } \\
\text { ratio }\end{array}$} & \multicolumn{2}{|c|}{$\begin{array}{l}\text { Cumulative } \\
\text { fiscal news }\end{array}$} & \multicolumn{2}{|c|}{ GDP growth } \\
\hline & Coeff. & $t$-stat & Coeff. & $t$-stat & Coeff. & $t$-stat & Coeff. & $t$-stat & Coeff. & $t$-stat & Coeff. & $t$-stat \\
\hline$\beta_{m}$ & -1.09 & & 18.5 & & 0.08 & & 0.11 & & -0.002 & & -84.2 & \\
\hline GR & $12.01 *$ & $4.8,3.2$ & 26.4 & $9.5,6.2$ & 0.05 & $1.9,0.9$ & 0.17 & $21,13.2$ & -0.03 & $-6.8,4$ & -61.0 & $-2.9,-1$ \\
\hline $\mathrm{BE}$ & -8.9 & $-5,-3.5$ & 32.7 & $5,3.2$ & -0.1 & $-4,-2.8$ & -0.09 & $-6,-4.3$ & -0.03 & $-1.3,0.8$ & 66.7 & $-1.4,0.9$ \\
\hline ES & -1.7 & $-0.6,-0.3$ & -1.1 & $-0.4,-0.2$ & -0.004 & $-0.2,-0.14$ & -0.01 & $-0.8,-0.5$ & 0.01 & $1.9,1.2$ & \multicolumn{2}{|c|}{$-136.1-2.8,-2$} \\
\hline FR & $49.5^{*}$ & $7.2,5.3$ & $-83.1^{*}$ & $-7.8,-5$ & 0.03 & $0.9,0.6$ & -0.02 & $-8.2,-6$ & $0.04 *$ & $5.3,4.7$ & 88.8 & $1.6,1.2$ \\
\hline $\mathrm{FN}$ & 3.0 & $1.3,0.9$ & $-38.6^{*}$ & $-4.6,-3$ & -0.04 & $-1.5,-1$ & -0.1 & $-4.2,-3$ & 0.02 & $1.6,1.2$ & 21.2 & $0.9,0.6$ \\
\hline IR & -2.9 & $-0.7,-0.4$ & -8.6 & $-2,-1.7$ & 0.03 & $1.9,1.7$ & -0.09 & $-8.7,-7$ & $0.03 *$ & $7.8,5.7$ & 83.6 & $3.9,2.8$ \\
\hline IT & 2.3 & $0.4,0.2$ & -6.8 & $-1.2,-1$ & -0.06 & $-1.5,-0.9$ & -0.005 & $-0.3,-0.1$ & -0.03 & $-1.2,-0.8$ & -61.2 & $-1.3,-0.7$ \\
\hline NL & -6.6 & $-1.7,-0.9$ & -10.6 & $-1.6,-1$ & 0.07 & $1.8,1.2$ & -0.08 & $-3.9,-2$ & 0.03 & $1.8,1.2$ & 66.3 & $1.4,1.1$ \\
\hline $\mathrm{OE}$ & 9.0 & $1.8,1.2$ & -6.8 & $-0.6,-0.4$ & -0.06 & $-1.4,-0.9$ & -0.07 & $-1.6,-1$ & -0.01 & $-0.03,0$ & -4.7 & $-1.2,-0.4$ \\
\hline$\underline{\mathrm{PT}}$ & $18.5^{*}$ & $5.6,3.7$ & $-38.5^{*}$ & $-8.1,5$ & 0.06 & $1.7,1.1$ & 0.01 & $1.3,0.9$ & -0.06 & $-9.9,-6$ & -81.8 & $-2.2,-2$ \\
\hline
\end{tabular}


Table 3 Pooling tests for each country

\begin{tabular}{|c|c|c|c|c|c|c|c|c|c|c|}
\hline Country & Belgium & Spain & Finland & France & Greece & Ireland & Italy & The Netherlands & Austria & Portugal \\
\hline $\begin{array}{l}F \text { test Critical } \\
\text { value at } 1 \% \\
\quad=1.8\end{array}$ & 3.6 & 0.16 & 1.1 & 3.3 & 26.5 & 12.9 & 0.2 & 0.8 & 0.3 & 5.8 \\
\hline
\end{tabular}


A similar picture emerges if we look at the cumulated news variable; the coefficient for Greece is both highly significant and negative; again, the results indicate that the markets reacted much more strongly to bad news regarding Greece than the other countries. When we then look down the column, all the other countries (except Belgium) have coefficients that are either positive or insignificant. Interestingly, Ire-land, which had the largest adverse news, has a positive and significant effect, which actually overturns the sign of the coefficient on cumulative fiscal news; the worse the news, the lower is the spread-indicating that markets reacted perversely to the bad news about the Irish fiscal deficit.

The final column considers the effect of GDP growth on spreads. Here again, Greece has a highly significant, negative, effect. A fall in growth in Greece raises the spread much more than in the other euro area countries. Again, when we look down the column we see that every other country (except Spain, which has a much smaller effect than that of Greece) has either a positive or insignificant coefficient. These results suggest that markets reacted much more strongly to news about Greece than to news for any other country.

It is interesting that, in some cases, the unpooled coefficient (the sum of $\beta_{\mu}+\beta^{*}$ ) takes on the wrong sign. This is true for cases in Table 2 which are bold and starred. Aside from the case of the Irish fiscal news variable noted above, Irish growth and the current account, this result typically occurs in northern countries. Thus, a deteriorating current account in France and higher relative prices in France and Finland led to falling spreads. Bad fiscal news and low growth in France and the Netherlands was associated with falling spreads.

As noted, the only fundamental variable with a wrongly signed coefficient is the fiscal-balance variable. Looking down the column of $t$-statistics for that variable, it can be seen that, with the exception of the case of Belgium, all $t$-statistics are insignificant. For Belgium, the $t$-stat is negative, and the magnitude of the coefficient - at -0.1 - overturns the pooled coefficient $(+0.08)$ so that the effect of the fiscal variable works in the correct direction.

The advantage of the above $t$ tests is that it tells us the direction in which the coefficients on each variable for each country moved in relation to the average. Con-sider, next, a joint test for pooling all the coefficients for each country, as reported in Table 3 . $^{5}$ That is, we test if all the coefficients for each country can be restricted to the average (pooled) value. The results clearly demonstrate that Greece, Portugal, and Ire-land were treated differently from the other countries. Although Belgium and France also fail the pooling test, as reported in Table 2 (dealing with individual coefficients), in most cases the coefficients for these two countries move in the opposite direction from those of Greece. For example, the pooled coefficient on the debt-to-GDP ratio in Table 2 is 0.11 , meaning that a rise in that ratio, on average, raises spreads. For Greece, the individual country effect (0.17) reinforces the pooled effect, whereas for Belgium and France the individual country effects $(-0.09$ and -0.02 , respectively) offset the pooled effects.

5 See Baltagi ( 2008), chap. 4, for a discussion of tests of hypotheses with panel data. 


\section{Conclusions}

If markets treated the sovereign debt of members of the euro area in an equal fashion, we would expect that a panel data model of spreads would obey the standard pooling assumption underlying the panel data estimation. In this paper, we have put forward a theory of the determination of spreads and found that this theory generally fits a fixed-effects panel data model well. However, when we tested the pooling assumption, we found that, at both the individual coefficient level and at the overall country level, Greece, Ireland, and Portugal were clearly not part of the overall pool. These results for individual countries and variables suggest that, in contrast to the theoretical model presented above, not all countries were treated identically when it came to pricing their fundamentals in sovereign debt markets.

Acknowledgments We are grateful to Harris Dellas for valuable comments.

\section{References}

Baltagi BH (2008) Econometric analysis with panel data, 4th edn. John Wiley, Chichester

Baltagi BH, Bresson G, Pirotte A (2008) To pool or not to pool, chap. 16. In: Matyas L, Sevestre P (eds) The econometrics of panel data: fundamentals and recent developments in theory and practise. Springer, Heidelberg

De Grauwe P, Ji Y (2013) Self-fulfilling crises in the Eurozone: an empirical test. J Int Money Financ 34:15-36

Gibson HD, Hall SG, Tavlas GS (2012) The Greek financial crisis: growing imbalances and sovereign spreads. J Int Money Financ 31:498-516

Pesaran MH, Smith R (1995) Estimating long run relationships from dynamic heterogeneous panels. J Econom 68:79-113

Pesaran MH, Shin Y, Smith R (1999) Pooled mean group estimation of dynamic heterogeneous panels. J Am Stat Soc Assoc 94:621-634 